\title{
ESTILOS CXS
}

DOI: https://doi.org/10.11606/issn.1981-1624.v25i3 p423-438.

\section{Dossiê}

\section{A controversa democratização do acesso ao ensino superior privado: o que dizem os professores na berlinda}

\author{
Isael de Jesus Sena
}

Resumo. É controversa a luta pela redução da desigualdade social por meio do acesso, dito democrático, ao ensino superior, sobretudo, privado. As instituições de ensino superior privadas de caráter quase mercantil pertencentes, hoje, aos grandes conglomerados educacionais, transformaram a formação universitária em um grande negócio lucrativo, cujo sistema de exploração inclui professores e alunos ao exigir de ambos uma cumplicidade perversa. Em entrevistas realizadas com professores universitários do contexto privado, eles revelam dramas e impasses submetidos ao ethos corporativo aplicado ao ensino, que exige do mestre a negação de sua experiência e de sua autoridade enunciativa. Assim, em nome da sobrevivência do mercado educacional, o professor aliena a sua subjetividade e torna-se instrumento a serviço da rentabilidade da privatização. A pesquisa aponta para a necessidade de revisão das políticas públicas de acesso à universidade e das formas de contratos de trabalho precários para os docentes.

Palavras chave: democratização; mercantilização do ensino universitário; universidade privada; professores; laço formativo perverso.

\section{La controvertida democratización del accesso a la educación superior privada: lo que dicen los profesores desde la silla de los acusados}

Resumen. Es controvertida a lucha por la reducción de la desigualdad social, a través del acceso democrático a la educación superior, sobre todo privada. Las instituciones de educación superior privadas de carácter tienen solamente quasi mercantil, pertenecientes hoy a los grandes conglomerados educacionales, transformaron la formación universitaria en un gran negocio lucrativo, cuyos sistema de explotación incluye profesores y estudiantes, exigiendo entre ambos una complicidad perversa. A partir de entrevistas realizadas con profesores universitarios, en este contexto, revelan sus dramas e impasses sometidos al ethos corporativo aplicado a la enseñanza, en la que se le exige al docente la negación de su experiencia y de su autoridad enunciativa. Así, en nombre de la sobrevivencia del mercado educativo, el profesor se aliena, pues se torna también instrumento al servicio de la rentabilidad del sector privado. La investigación apunta sobre la necesidad de revisión de las políticas públicas de acceso a la universidad y a las formas de contratos de trabajo precarios para los docentes.

Palabras clave: democratización; mercantilización de la enseñanza; universidad privada; profesores; lazo formativo perverso.

*Psicólogo e psicanalista. Doutorado em Ciências da Educação pela Universidade Federal de Minas Gerais (UFMG) e Université Paris 8, pós-doutorando pela Université de Paris 8 Vincennes - Saint-Denis, França. Email : senaisael@gmail.com 


\title{
The controversial democratization of access to private higher education: what teachers say on the spot
}

\begin{abstract}
The struggle to reduce social inequality through the so-called democratic access to higher education, above all private, is controversial. Private higher education institutions of mercantile character, belonging today to the large educational conglomerates, have transformed university education into a large profitable business, whose operating system includes teachers and students, demanding between them a perverse complicity. From interviews with university professors in this context, they reveal their dramas and impasses underwent to the corporate ethos applied to teaching, in which the professor is required to deny his experience and his enunciative authority. Thus, in the name of the survival of the educational market, the teacher alienates his subjectivity, as well as becoming an instrument at the service of the profitability of privatization. The research points to the need to review public policies for access to university and the forms of precarious employment contracts for teachers.

Keywords: democratization; commodification of education; private university; teachers; perverse formative bond.

\section{La démocratisation controversée de l'accès à l'enseignement supérieur privé: ce que disent les professeurs sur la sellette}

Résumé. La lutte pour la réduction de l'inégalité sociale grâce à l'accès, dit démocratique, à l'enseignement supérieur, en particulier privé, est objet de controverse. Les institutions d'enseignement supérieur privées au caractère largement mercantile, appartenant, aujourd'hui, aux grands conglomérats éducationnels, ont transformé la formation universitaire en une grande entreprise lucrative, dont le système d'exploitation implique les professeurs et les étudiants, en exigeant d'eux une complicité perverse. Au cours d'entretiens réalisés avec des professeurs universitaires du privé, ceux-ci révèlent des drames et des impasses, soumis qu'ils sont à l'ethos corporatif appliqué à l'enseignement, qui exige du maître le déni de son expérience et de son autorité énonciative. Ainsi, au nom de la survie du marché éducationnel, le professeur aliène sa subjectivité et devient un instrument au service de la rentabilité de la privatisation. L'étude souligne la nécessité de révision des politiques publiques d'accès à l'université et des types de contrats de travail précaires des enseignants.

Mots-clés: démocratisation; mercantilisation de l'enseignement universitaire; université privée; professeurs; lien formatif pervers.

A política de ampliação do ensino superior e as suas diferentes formas democráticas de acesso à universidade tiveram amplo alcance nos últimos anos. É inegável que isso seja resultado de um processo historicamente datado, cujo ponto de partida deu-se com a retomada da redemocratização do Brasil, após longos anos de ditadura (1964-1985), iniciada pelo expresidente Fernando Henrique Cardoso (1995-2003) ao implementar um conjunto de políticas públicas que possibilitaram a expansão dos sistemas de ensino primário e secundário, com repercussão no âmbito universitário. Em continuação ao trabalho do governante anterior, Luiz Inácio Lula da Silva (2003-2011) e Dilma Roussef (2011-2016) também foram responsáveis pela expansão do sistema federal de ensino e por expressivas matrículas nos ensinos público e privado, pois possibilitaram a construção de um laço social a partir da oferta de acesso à educação em todos os níveis de ensino, principalmente, aos grupos de origem popular (Sena, 2020).

No entanto, é controversa a maneira como fora conduzida a luta contra a desigualdade social - essa profunda "patologia brasileira" - sobretudo, por meio do acesso, dito "democrático", a instituições privadas de caráter mercantil. A nossa hipótese é que a mercantilização da formação universitária, ao tratar o aluno como cliente e o professor como fornecedor de um serviço/ensino, perverteu as coordenadas simbólicas envolvidas na relação entre mestres e discípulos. Em nome de sua sobrevivência no mercado da formação universitária, o professor 
aliena a sua subjetividade como um instrumento a ponto de tornar-se um complacente da montagem perversa com o estudante, pois há uma impostura adotada pela instituição de ensino, na medida em que o docente se coloca a serviço da rentabilidade da privatização. (Sena, 2020)

Neste artigo, buscamos refletir sobre as condições políticas, institucionais e subjetivas resultantes dessa formação acadêmico-profissional. Com base em relatos de professores entrevistados, empregados de uma instituição de ensino superior privada, enfatizamos as experiências docentes na relação com a faculdade, os alunos e a transmissão.

Ao examinar os impasses do atual regime republicano, podemos observar que a "igualdade moderna" ainda é um pesadelo em nossa "quase-república", pois a promessa de um lugar no pacto social ainda é realizada por iniciativas que reproduzem a segregação e reforçam, assim, a desigualdade histórica. A massificação da formação universitária ainda é construída segundo a "lógica do condomínio" (Dunker, 2015); a educação sob a forma de apartheid social. Desse modo, o aumento significativo do número de matrículas de jovens que se tornaram "clientes" do mercado universitário não incidiu, como era esperado, sobre o quadro de desigualdade social característico do Brasil. Nesse sentido, concordamos com Lacan (1969-70/1992), uma vez que as transformações produzidas pela sociedade, em cada época, fizeram-no acreditar que ainda não terminamos com a segregação, ao invés disso, seus modos de funcionamento reaparecem com mais força.

Nesta discussão abordaremos: o laço social sob a forma de um igualitarismo perverso na universidade, dita "democrática"; as condições que engendram a universidade sob o ethos corporativo; o mercado perverso como reprodução da segregação; a incidência da virtualidade e o deslocamento do lugar de enunciação do professor; e, por fim, o professor e a perversão do laço formativo.

\section{A universidade "democrática": o laço social sob a forma de um igualitarismo perverso}

Em diferentes latitudes, com problemas específicos, o debate sobre a Universidade e os seus desafios atuais, no dizer de Boaventura de Souza Santos (2011), revela que a universidade encontra-se em uma encruzilhada. O problema se deve ao fato de que a instituição vive um processo de transição paradigmática. Enfrentamos problemas modernos para os quais não temos soluções modernas. Isso significa que a prossecução dos ideais da Revolução Francesa - liberdade, igualdade, fraternidade -, nos últimos dois séculos, não conseguiu alcançar o senso de justiça social, de modo pleno, nem na Europa nem no resto do mundo. Por outro lado, as soluções encontradas não conseguiram concretizar os objetivos maiores pelos quais combateuse a desigualdade social arduamente.

No Brasil, uma pauta central e também problemática, diz respeito ao modo como realiza-se a "inclusão" de jovens, oriundos da classe social popular, que passaram a ter acesso à universidade pública, seja por meio do sistema de cotas, seja pelo Sistema de Seleção Unificada (SISU), oportunizados a partir da realização do Exame Nacional do Ensino Médio (ENEM). Outro elemento, igualmente importante, foi a política de expansão das instituições federais colocadas em curso pelo Programa de Apoio a Planos de Reestruturação e Expansão das Universidades Federais (REUNI) ${ }^{1}$. Um passo decisivo que contribuiu para a interiorização do

Quando estabelecemos um contraste entre os governos, no período de 1998 a 2003, correspondente ao segundo mandato de FHC, percebemos a existência de 158.461 novas matrículas. Além disso, de 2007 a 2010, período que corresponde ao segundo mandato Lula, exatas 478.857 novas matrículas foram registradas nas universidades federais. Assim, se 
ensino, pois ampliou as chances de oportunidades de acesso à universidade pública. O conjunto dessas políticas públicas, implementadas pelos governos de esquerda, teve como ideia central o esforço civilizatório para reduzir a desigualdade social por meio da construção de um laço social que possibilitaria a igualdade de direitos em uma instituição historicamente elitista.

No entanto, é preciso interrogar o modo como ocorre essa "inclusão". O acesso, dito democrático, às Instituições de Ensino Superior Privadas - como faculdades isoladas, centros universitários, entre outras -, vem sendo feito com a oferta de bolsas pelo Programa Universidade para Todos (PROUNI), além de contar também com o Programa de Financiamento Estudantil (FIES). Trata-se de uma expansão financiada pelo Governo Federal. Ao observarmos, especificamente, as características de parte significativa das instituições privadas de cunho estritamente mercadológico, constatamos que estão centradas no ensino, sem qualquer tradição de pesquisa. São estabelecimentos que constituem hoje parte dos conglomerados educacionais e possuem um caráter tão somente mercantil. Ademais, integram o capital externo, além de serem questionáveis quanto ao critério da qualidade da formação universitária. "Esta qualidade nunca vista, mas sempre perseguida, não guarda relação alguma com nenhum dos objetivos praticáveis e facilmente constatáveis" (Lajonquière, 2018, p. 60).

Além disso, a mercantilização do ensino confirma o "declínio do sentido público da educação", que ocorre em contraposição a uma diluição evidente das fronteiras entre os domínios público e privado como efeito da ascensão da sociedade de consumidores submetida aos imperativos econômicos e à perda de seu significado ético-político. (Carvalho, 2017)

O recente Censo Escolar de 2017 (Brasil, 2018) apontou que existem, ao todo, 2.162 instituições privadas, com a seguinte organização acadêmico-administrativa: universidades privadas $^{2}$ (93), centros universitários (181), faculdades privadas (1.878). As instituições públicas perfazem o total de 296 unidades (federais, estaduais e municipais). Assim, 87,9\% das instituições educacionais existentes são privadas. 8.652.441 alunos estão matriculados na rede privada, enquanto 2.352.232 estão na rede pública. A rede privada conta com mais de 6,2 milhões de alunos. Isso representa uma participação acima de $75 \%$ do sistema de educação superior. A cada 4 estudantes de graduação, 3 frequentam uma instituição particular. Ao observar essas estatísticas, presume-se, pelos números, o peso do espírito neoliberal. A globalização do mercado possui uma retórica particular: "tem valor porque vende bem".

Curiosamente, nesse mesmo contexto, entre os cursos de licenciatura, a pedagogia destacase com o expressivo contingente de 710.855 matrículas. $O$ perfil dos alunos é predominantemente feminino: um percentual de $70,6 \%$, contra $29,4 \%$ masculino. $62,1 \%$ das matrículas concentram-se nas instituições privadas, enquanto 37,9\%, nas públicas (Brasil, 2018). Salientamos ainda que, em "um curto intervalo de tempo, as instituições privadas muitas delas sem tradição alguma na oferta de cursos de licenciatura - passaram a responder quantitativamente pela formação de professores da educação básica no país" (Diniz-Pereira, 2015 , p. 274). Na rede privada, prevalecem os cursos a distancia, com quase $65 \%$ dos alunos (Brasil, 2018).

contrastados os períodos equivalentes, constata-se que o operário Lula abriu $200 \%$ mais novas vagas em universidades federais do que o intelectual FHC. (Almeida Filho, 2010).

O sistema universitário privado no Brasil não é homogêneo. Quando falamos em universidades privadas temos que considerar a sua diversidade, diferenciação e diversificação. Sampaio (2014) assinala que a Constituição da República do Brasil, em 1891, disciplinou a possibilidade de existência do ensino superior privado, que permitiu uma organização dual no sistema. De um lado, um setor público e gratuito, cujas instituições são mantidas pelos poderes federal, estadual ou municipal; de outro, um setor privado, constituído por estabelecimentos mantidos por entidades de natureza jurídica privada - laicas comunitárias ou confessionais de credo (católicas, protestantes etc.) - subordinadas a uma legislação federal. 
Ao examinar os percursos, verificamos que vários alunos, cujo processo de escolarização deu-se com sérios problemas pedagógicos e de aprendizagem, buscam cursos de licenciatura por considerar poucas as exigências para o ingresso no ensino superior. Como as opções são mais restritas para esses alunos, alguns têm a chance de chegar à formatura e, enfim, tornar-se professores. Porém, entre esses alunos que escolhem o curso de licenciatura, há aqueles que evadem. Por isso, são poucos os que realmente identificam-se com a profissão e passam a realizá-la com desejo (Pereira, 2019).

A solução, dita democrática, com a qual busca-se produzir um igualitarismo, por meio do acesso ao ensino universitário privado, opera sob duas formas de reconhecimento do outro marginalizado pelo laço social. A primeira é a inclusão operada pela lógica do mercado segundo a qual alguns jovens poderão distanciar-se de suas origens pobres. Para Kehl (2000), o mercado vende a imagem de que o jovem da periferia pode ser investido narcisicamente e ainda pode servir como objeto de identificação e consolo para as grandes massas que sonham em também contar com a sorte de um dia virarem exceção. A segunda corresponde à posição de exceção e, ao mesmo tempo, de excentricidade, que constitui uma parte de nosso mito de brasilidade, seja pelo ufanismo, seja pelos "artefatos" utilizados para o "inglês ver". Nossas políticas educativas são baseadas ora na carência, como correlato da deficiência, ora na reparação, mas sob a forma de um dualismo perverso baseado no apartheid. Em última análise, trata-se de uma falta de reconhecimento do outro na dinâmica própria desta sociedade que conserva seus traços ainda escravistas. Essa evidência é verificada, diariamente, nas instituições e nas relações de nossa "psicopatologia da vida cotidiana".

Nossos personagens da exceção tornam-se alvos hoje do apetite de gozo do mercado educacional. Ao considerar o hiato da desigualdade histórica e socialmente produzida, o carrochefe emblemático do Programa Universidade para Todos visa tornar todos os "excluídos" (negros, índios e deficientes) do laço social com "potencial" de inclusão em um projeto político educacional de "reparação". Se considerarmos a temporalidade histórica, podemos observar que, embora a política do colonialismo não exista mais, esse tipo de fosso e de obstáculo ainda serve como matriz de nossa organização subjetiva a ponto de confirmar a especulação de Calligaris (1991), segundo a qual o colonizador e o colono constituem duas figuras retóricas dominantes no discurso do brasileiro e compõem tanto o quadro como a estrutura dos lugares possíveis de enunciação no Brasil. Assim, cada sujeito enunciador assumirá um desses lugares. Isso é parte de nosso sintoma nacional.

Essa construção de laço social sob a forma de exploração, em que somente o interesse do mestre prevalece, remete-nos ao mito de Totem e tabu (Freud, 1913/1996). O pai da horda primitiva era uma figura de excesso que monopolizava a potência da comunidade sob o seu jugo e a serviço de seu prazer. Por isso, os demais estavam entregues à própria sorte, sob a forma de impotência, exclusão e marginalização. Apesar dessa tirania perpetrada pelo pai, ele oferecia, em troca, uma proteção, uma hierarquia de normas e valores, ainda que, para garantilas, produzia também desagregação e instabilidade.

Diante da onipotência paterna, não restava à prole outra saída diferente da união protofraterna - a união dos fracos e excluídos. É exatamente, a partir daí, que o assassinato do pai torna-se possível, pois funda a ordem do laço social e cria as condições de práticas civilizatórias sustentadas pela solidariedade fraterna ao permitir o reconhecimento das obrigações mútuas. A cultura ou a civilização será a condição de uma busca cotidiana e generalizada das felicidades possíveis no campo mais resguardado da convivência socialmente instituída (Figueiredo, 2000). Além do mais, "a concessão de direitos iguais a todos os membros da aliança fraterna - isto é, 
a restrição da inclinação para a rivalidade violenta entre eles. Nesses regulamentos, devem ser vistos os primórdios de uma ordem moral e social" (Freud, 1913/1996, p. 134).

O mito, retomado por Freud (1913/1996), ajuda-nos a compreender determinadas configurações sociopolíticas, sobretudo, aquelas promessas disseminadas pelas reformas educacionais que pretendem promover uma "aliança igualitária de direitos", segundo a qual a "fraternidade dos excluídos" alcançaria o sonhado reconhecimento com o acesso ao diploma. Mas, o que dizem os professores que exercem a docência em instituições mercantilizadas?

\section{O professor e a fábrica de diplomas: o mercado perverso}

Neste cenário de mercantilização da formação universitária, evocamos o fragmento de uma entrevista realizada com o professor de engenharia civil, João $\operatorname{Carlos}^{3}$, que lecionava há 4 anos na instituição onde ocorrera o nosso trabalho de campo ${ }^{4}$. Ao fazer o diagnóstico de seus alunos, ele chegou à fatídica constatação:

\footnotetext{
Os alunos chegam com o sonho de abrir o próprio negócio ao sair da faculdade. Mas a gente sabe que a maioria não poderá comprar uma empresa própria, porque terá a dívida do FIES para quitar, e não arranjará um emprego. Sabemos que algumas empresas selecionam o candidato pelo tipo de faculdade que ele cursou. Boa parte de nossos alunos é de baixa renda, depende do financiamento e das bolsas. Os alunos reclamam, só reclamam. Mas não fazem a parte deles [...] Eles têm dificuldade em realizar operações simples de matemática. Frustram-se porque querem ser os melhores técnicos do mundo, mas descobrem que, lá fora, há um 'monte' de técnico bom e que ser profissional não é só isso. E, aí, há aquele que larga a profissão, frustra-se e vai procurar a terceira, a quarta, a quinta coisa porque ainda não encontrou o mapa da mina. Muitos alunos estão procurando o mapa da mina e, talvez, ele não exista. " $90 \%$ [dos alunos] saem para continuar sendo caixas de supermercado, cobradores de ônibus ou para continuar fazendo o que sempre fizeram. Eles têm o diploma, mas não vão ser nada na vida. Eles não sabem aproveitar o tempo. Deveriam estudar, aprender. Mas, só estão querendo se formar para ter uma esperança de mudar de vida. (Professor João Carlos, 2017).
}

Nesse excerto, contundente, o professor mostra a outra face da cidadania do igualitarismo. O imaginário social disseminado pelos artifícios das propagandas das faculdades baseia-se na máxima: cada um pode "tornar-se dono de seu próprio negócio". Com efeito, a dívida contraída pelo financiamento estudantil impossibilita ao aluno concretizar o sonho da promessa neoliberal de autonomia e de tornar-se empreendedor de si. A ilusão vendida pelo mercado sustenta-se em uma certa crença, segundo a qual tudo passa a ser regulado pelas escolhas individuais. No entanto, a evidência da competitividade é reiterada pelas empresas que adotam mecanismos internos de seleção excludentes, pois o contratante "seleciona pelo tipo de faculdade que o candidato cursou". O diploma perdeu seu valor simbólico e o reconhecimento como atestado de acesso ao trabalho digno. Como atesta Lajonquière (2011a), o diploma deixou de ser uma chave abridora de futuros, quando ainda funcionava como significante de uma

\footnotetext{
Nome fictício, bem como os demais.
}

4 Esses relatos fazem parte da pesquisa empírica realizada durante meu doutoramento (2016-2020). O trabalho de campo ocorreu durante os meses compreendidos entre maio e agosto de 2017 e foi realizado em uma instituição privada localizada em uma capital do Nordeste. No total, foram entrevistados 42 (quarenta e dois) professores de várias disciplinas. A pesquisa seguiu os trâmites das diretrizes e normas regulamentadoras de pesquisas que envolvem seres humanos outorgadas pela Resolução 466/12 do Conselho Nacional de Saúde e foi aprovada pelo Comitê de Ética na Pesquisa (COEP)/UFMG, sob o número CAEE - 66241417.0.0000.5149. 
esperada transformação existencial. Mas, hoje, se ele é ganho, vale quase nada. Aqueles que valem podem ser comprados e, portanto, perdem seu valor. $\mathrm{O}$ sonho difuso de um futuro diferente esfumou-se.

Nesse mercado universitário veicula-se que é suficiente ter acesso ao diploma, conforme a lógica da esperança do gozo do utilitarismo. Ademais, basta a manifestação da insatisfação para que uma nova matrícula seja realizada. A socialização disseminada não resulta em dívida para as referências simbólicas. O paradoxo é que os alunos "querem se formar para mudar de vida". Em contrapartida, o professor se ressente diante da constatação de que os discentes "não sabem aproveitar o tempo". Suspeitamos que esse desinteresse revela uma face do apagamento do desejo. O lema "pagou, passou" desobriga o aluno de investir com a sua "capital da libido" (Lacan, 1969-70/1992). Supostamente, essa relação conhecimento-mercadoria é um claro sinal, uma demonstração de que os estudantes parecem mostrar "desejo de não saber". O professor atesta que os alunos mostram-se apáticos e, provavelmente, sem "fome de saber", além de apresentarem limitações no percurso formativo.

Teixeira (2013), longe de ser determinista, supõe que um percurso de vida e de educação culturalmente empobrecidos, que não favoreça a sublimação e os processos de simbolização, poderia comprometer o desejo de saber. Mas, Sampaio (2011), no observatório que estuda a biografia de alunos ingressantes na universidade pública, por meio de políticas afirmativas, atesta que eles tiveram uma formação de base precária em um contexto cultural desfavorecido e, ainda assim, sustentaram o desejo decidido de estudar e ingressar na universidade, pagando subjetivamente para que isso fosse possível. Alguma coisa se passou com eles, algo que não se passa, necessariamente, com os outros estudantes.

Outro aspecto, igualmente importante, do relato de João Carlos diz respeito aos alunos que não conseguem a inscrição e a obtenção de reconhecimento no mercado profissional, pois são subcontratados. Provavelmente, essa maneira perversa de democratização produziu sujeitos "excluídos do interior", em alusão a Bourdieu e Champagne (1993/2008). Assim, a promessa de um lugar no pacto social acabou reforçando a mesma desigualdade histórica que se pretendeu superar. O tipo de laço social estabelecido, conforme o viés neoliberal, é aquele segundo o qual o outro sequer é reconhecido, reduzido ao lugar de resto 5 .

A impostura dessa "política educativa" consiste no seguinte fato: a sonhada busca pelo reconhecimento da "igualdade moderna" torna-se um pesadelo, porque a mistificação da terra prometida torna-se uma cadeia que serve para alimentar os empresários da educação - o novo colonizador. As medidas que fomentaram o ensino superior privado, adotadas pelos governos, parecem uma "perversa cultura de direitos que em nome da defesa do fraco cria uma indústria da trapaça" (Abraham, 1997, p. 58).

\section{A universidade segundo o ethos corporativo: a professora e a aluna "tutelada"}

O ethos corporativo, próprio da gestão empresarial, costuma ser aplicado sem criticidade à formação universitária. As demandas administrativas, institucionais, pedagógicas e tecnológicas expropriam a autoridade enunciativa do professor. $\mathrm{O}$ ensino equivale a uma mercadoria e o professor é um instrumento dessa lógica discursiva, pois ele trabalha a serviço

5 Esse debate acerca do desemprego de jovens universitários pode ser aprofundado a partir dos recentes dados do Instituto de Pesquisa Econômica Aplicada - IPEA (Brasil, 2019). 
da outorga da "fábrica de diplomas". A lógica do aluno/cliente/consumidor pressupõe que o professor renuncie a sua autoridade e seja obediente à prescrição do mercado, como esclarece a professora Isolda:

Tive um caso mais recente: eu tinha uma aluna reprovada em banca de Trabalho de Conclusão de Curso por conta de plágio. Ela teve muitas chances. Era uma aluna que usava os argumentos de que tinha Transtorno de Déficit de Atenção e Hiperatividade (TDAH) e de que tomava medicamento. Ela era toda enrolada, daquelas que se matriculam, mas faltam o tempo todo. Depois de um mês que começou a aula, ela apareceu. E, daí, os pais dela, que são empresários e têm amigos influentes em grandes escritórios de advocacia, entraram com processo contra a faculdade, alegando que a gente não indicou que era plágio. Mas, eles não contavam com a minha sorte. Na relação com o aluno hoje a gente tem que juntar provas, tipo polícia (risos), tem que manter todas as provas arquivadas. Então, a minha sorte é que eu tinha as três versões dos TCC's corrigidos, de três professoras diferentes. Eu era a professora da disciplina. A orientadora e mais a banca, uma outra professora que foi banca. Nós tínhamos tudo arquivado. Então, não basta mais a nossa palavra ou a nossa avaliação. Hoje, você precisa provar por $\mathrm{A}+\mathrm{B}+\mathrm{C}+\mathrm{X}$ que aquele aluno não tem condição de ser aprovado, não tem condição de, por exemplo, passar por uma banca de TCC. Eu e os meus colegas das outras faculdades da região $\mathrm{X}$ estamos todos dizendo que isso tem se tornado um pepinão [problema] (Professora Isolda, 2017).

Um dos problemas enfrentados pelo professor na universidade privada é o fato de que o aluno, além de mostrar-se desinibido e desrespeitoso, não assume a responsabilidade por sua formação, pois conta com a interferência dos pais como cúmplices frequentemente nas formas de escárnio perante a autoridade do professor. No excerto apresentado, a professora Isolda mostra que o TCC fica esvaziado de reflexão ética, de ser rito de passagem, uma marca da conclusão de um percurso formativo e a passagem para o mundo profissional, pois o aluno também deve dar provas de que aprendeu a natureza de um trabalho científico. A atividade acadêmica torna-se, portanto, desqualificada. Além disso, pede-se ao professor, de modo incompatível com o seu exercício, que não transmita ao aluno qualquer sinal de frustração, que seja cúmplice e benevolente, sob o risco de ser destituído. Desse modo, o professor é colocado em uma berlinda.

A lógica do conhecimento-consumo-satisfação intimida a professora a exercer a docência em uma posição de constante hipervigilância, uma vez que precisa sempre antecipar-se aos atos possíveis. Diante da iminência de ser submetida a avaliação, a docente desenvolve uma "paranoia" de perseguição, ao reunir provas e mantê-las "arquivadas", como se fosse da "polícia", pois pressupõe, com isso, ter condições de responder, judicialmente, quando uma resposta for requerida. A situação vivenciada pela professora remete aos balcões de justiça, quando os consumidores, insatisfeitos com as garantias, reivindicam seus direitos. Embora o aluno não tenha as condições acadêmicas para ser aprovado, o professor será contestado, como em um balcão de negócios. Em nome da cultura do "direito" como um imperativo do aluno, Teixeira e Almeida (2016) apontam que o aluno tem o direito de não se entediar, de não se frustrar, de não ser incomodado e de poder gozar a qualquer custo.

A interposição dos pais frente aos atos dos filhos "adultos" na faculdade, tutelando-os, levanos a supor que alguns jovens demonstram não serem suficientemente autônomos para ocupar o lugar adulto. Provavelmente, o caso citado é um exemplo do dilema, chamado por Pereira e Gurski (2014) de "adolescência generalizada", como sintoma de nossa época. Uma adultez erodida sem marcos culturais ou significantes claros que a demarquem.

O tutelamento dos pais aos filhos encontra apoio nas formas de apelo ao discurso jurídico que visa judicializar os problemas de ordem acadêmico-profissional tratados sob a lógica do 
consumo. Para Figueiredo (2000), esse é um típico retrato de que, frente a qualquer frustração, há sempre um "pai" e uma "mãe" explícita ou implicitamente invocados, imitados ou "amansados" na solução dos problemas pela via transgressiva. Quando não são pais “excessivos", são generosos, cujo imperativo que prevalece, segundo Racamier (2010, tradução nossa), é o incestuel, o que não implica um ato genital, mas uma série de comportamentos cotidianos que não permitem definir os limites.

Infelizmente, a elite nacional, diz Kehl (2002), está acostumada a conviver com uma série de práticas ilegais de maior ou menor gravidade, posto que a lei serve apenas para enquadrar $o s$ outros. Os jovens convivem com infrações naturalizadas pela família. É o pai que oferece suborno, caixinha, ao guarda para escapar de uma multa de trânsito ou pede a cabeça do professor que reprovou, por razões justas, seu filho. O que se transmite é que o dinheiro compra até o que não tem preço: a vergonha, a educação, a lei. "Se eu pago, eu posso", diz o pai de família burguês aos seus rebentos, sem imaginar que é por esse caminho que sua autoridade desmoraliza-se.

A forma de laço social perverso predomina, o Outro já não se revela consistente de modo que possa fazer barreira ao empuxo do gozo, sobretudo, veiculado pela promessa propagada da formação universitária, segundo o ethos empresarial aplicado à educação. A partir da máxima do mercado, a autoridade do professor é demovida em nome de interesses privados, particulares. Esse resíduo colonial predomina ainda no substrato das relações institucionais, de modo geral, e na vida cotidiana do Brasil, sob a forma de exploração. Podemos chamar de extensão da "mentalidade de casa-grande" que adentra às universidades.

\section{A universidade privada sob o triunfo da virtualidade: o papel funcional do professor}

À medida que a universidade democratiza as suas diversas formas de acesso, dissemina-se também a ideia segundo a qual deve-se universalizar os saberes, mas prescindir da palavra professoral. A maneira como são implementadas as Novas Tecnologias da Informação e Comunicação (NTIC) pressupõe a substituição da presença física do professor. Os administradores das instituições de ensino entendem que é suficiente o imaginário tecnomaquinário para disseminar as informações, embora isso não signifique que as instituições prezam pela difusão do conhecimento. O professor, portanto, é convocado a assumir um papel funcional.

Seguindo o raciocínio anterior, duas portarias publicadas em momentos distintos contribuíram, ao longo desses anos, para flexibilizar e precarizar o trabalho docente. Em 2004, a primeira portaria, publicada pelo Ministério da Educação, autorizava a liberação de $20 \%$ das disciplinas em formato semipresencial. Decorridos mais de 14 anos, em 2019, a segunda ampliou o percentual para $40 \%$. Essas medidas governamentais geraram incertezas, sofrimento e até a demissão de professores, especialmente, de empregados horistas, aqueles que têm a remuneração calculada por hora de trabalho, ou dos de tempo parcial. Ademais, semestralmente, as disciplinas precisam ser barganhadas com o coordenador do curso, haja vista que, na ausência de captação de novos clientes, o professor deve assumir disciplinas não relacionadas com a sua especialidade. Observemos o que nos diz a professora Julieta:

Eu lecionava a disciplina de ética e fui demitida porque a aula virou virtual. Quando eu saí daqui [faculdade], depois que assinei a minha carta de demissão, eu falei: "Meu Deus, o que 
farei amanhã sem esses alunos?". Às vezes, dá muito trabalho, a gente fica cansada demais, a falta deles é incrível. Eu fui para casa angustiada (Professora Julieta, 2017).

Sabemos que as demissões nem sempre têm causas justas, embora as motivações empresariais sejam justificadas em nome da racionalização dos recursos. No caso supracitado, decorridos dois semestres após a demissão da professora, ela foi contratada novamente. Os novos alunos do semestre subsequente fizeram um abaixo-assinado para exigir ao coordenador do curso que a disciplina fosse ministrada presencialmente e com a mesma docente, por duas razões: a primeira era a implicação daquela disciplina no ensino; a segunda era o fato da professora demitida ser servidora pública de um importante serviço e conseguir, por esse motivo, mediar o acesso de muitos alunos às formas de estágio e de visita técnica. Como os requerentes eram alunos com alto poder aquisitivo, capazes de pagar uma mensalidade exorbitante, a instituição cedeu aos interesses "coletivos".

No entanto, isso não é uma regra, uma norma que vale para todos os cursos. A resolução de ceder parece revelar que a instituição adota formas desiguais de tratamento para as demandas dos alunos/clientes a depender do status do curso. Em um curso de administração, a decisão de mudar a forma de oferta da disciplina presencial para a modalidade virtual foi arbitrária:

Eu dava essa disciplina muitos anos atrás, depois ela se tornou interativa, aí fiquei frustrada. Porque... Sabe aquela matéria que é toda redondinha, as aulas são "super" bem montadas e, de repente, me tiram. Eu me senti frustrada, roubaram de mim, não é possível. Era a disciplina que eu mais gostava de dar. Eu me programava para receber visitantes. Eles faziam palestras. $\mathrm{E}$, aí, entra aquela velha história, as faculdades não estão preocupadas com a qualidade. Eu tentei argumentar: "mas essa disciplina tem tanta troca de exemplos, de experiência, tem que ser presencial". E, aí, não teve argumento. A coordenadora disse "eu também concordo, mas não posso fazer nada". Veio de cima [ordem do diretor], virou interativa (Professora Perséfone, 2017).

Sob a ótica da lógica mercantilista, as justificativas para a transposição das disciplinas para o formato interativo, virtual, são decisões, em princípio, que sequer passam pelo diálogo entre os pares, tampouco há consulta ao "colegiado". O que essas decisões administrativas atestam é que as formas de gerencialismo aplicadas irrestritamente ao ensino corroem a própria essência da transmissão. Como observa Aladipani (2011), o problema da inserção da lógica gerencial no meio educacional é que ela passa a impor um "ethos" corporativo para um tipo de atividade que pouco ou nada tem a ver com o mundo das empresas. Dentro desse raciocínio, dispensa a noção de tempo necessária para que o professor possa amadurecer suas ideias. Além disso, sabemos que ensinar requer liberdade para transmitir a própria experiência sem a preocupação de ter que agradar um cliente ou um patrão.

Em um esforço de síntese, a professora Patrícia declara que:

[...] Os currículos são afunilados para responder a essas demandas. O assunto vem engessado. Já vem tudo pronto. A gente tem que enfiar na cabeça do aluno. O professor não tem o direito de fazer uma aula. Eu observo que os alunos assistem aos vídeos, mas voltam cheios de dúvidas. A instituição pegou uma disciplina complexa e colocou virtual. Pode uma coisa dessa? E ainda me contratou para ser tutora presencial porque os meninos não estavam entendendo nada. Você paga uma instituição presencial, mas $20 \%$ das disciplinas são online. A disciplina de metodologia científica é "super" importante, eu observo que o aluno encara como um passatempo. Ele fica enchendo o currículo. Há disciplinas EaD que são boas, mas os alunos não entendem o assunto (Professor Patrícia, 2017).

Esse testemunho de Patrícia parece, por um lado, resumir os muitos desafios atuais porque passam os professores frente à avalanche do triunfo da virtualidade, pois supõe-se que os 
estudantes correspondem ao "paradigma autoinstrucional" da cultura digital, em que o aluno se torna o único responsável em gerenciar o seu tempo de estudo. Por outro lado, parece revelar a maneira perversa como as instituições privadas têm conduzido o processo de transição de disciplinas para o formato interativo. Os currículos são "afunilados" e "engessados" porque "já vem tudo pronto". Com essa afirmação, presume-se que, ao participar do cinismo, o professor universitário se desobriga de negar, em sua transmissão, uma certa marca ligada à tradição. Além disso, ele é convocado a ocupar um lugar, mas sob a renúncia professoral, pois "conhecimento, saber, desejo e dívida simbólica" (Lajonquière, 2010/2013, p. 109; tradução nossa), como pressupostos que deveriam estar articulados a toda educação que se preze, aparecem disjuntos na mercantilização da formação universitária.

Nesse sentido, a relação estabelecida como marca de um ensino "supostamente" eficaz e atento às competências do aluno exclui a dimensão do desejo do professor e do estudante, empobrecendo, assim, a experiência para ambos, considerando que se trata de "um processo aberto de passagem de uma posição a outra no campo da palavra e da linguagem, um giro trans/formador de discípulo a mestre" (Lajonquière, 2011b, p. 851). Se a educação resulta em deveres e débitos, se o mestre renuncia ou esquece de manter viva a lembrança da sua dívida existencial e se, além disso, abre mão da dignidade do seu ensino, o mundo dos números vira letra morta e o mestre perde um pouco de seu ser (Lajonquière, 2009).

Ao transformar "uma disciplina complexa" em conteúdos interativos, virtuais, a instituição despreza o papel que a transferência exerce sobre discípulos e mestres para instalação do desejo de saber. Além de enfraquecer a relação do estudante com a alteridade, este fica liberado de, ao entrar na vida universitária, não ser convocado a se implicar subjetivamente diante dos desafios próprios da formação acadêmica. Assim, temos a impressão, como mostra-nos Lo Bianco (2010), de que não há mais enigma decifrável. A verdade está dada, aberta e pode ser acessada a qualquer hora e em qualquer lugar. O computador torna-se o parceiro ideal. Tudo parece resumir-se à constatação, feita por Bellenagé (2007, tradução nossa), de que a evolução cultural modificou a relação entre o saber e as modalidades de sua transmissão em uma sociedade, dita de consumação. Nessas formas de laço social em que prevalece o gozar, o saber torna-se, essencialmente, saber-fazer. Logo, trata-se de uma relação de rentabilidade que deve ser o mais imediata possível, ou seja, de consumo sem moderação.

Supreendentemente, a lógica do não todo contraria o império da virtualidade: a professora Patrícia confirma que "os alunos assistem aos vídeos, mas voltam cheios de dúvidas". Ademais, essa professora também foi demitida e, alguns semestres depois, contratada novamente incluída em um novo plano de salário, de valor mais baixo, para trabalhar como "tutora presencial", dado que comprova a realidade da precarização das relações trabalhistas. Em suma, como afirma Voltolini (2019), é curioso que o mesmo poder, contestado e subtraído no interior da relação pedagógica, no nível de direito, retorna para o professor, paradoxalmente, como 'exigência de potência' frente ao fracasso dos alunos que não conseguem aprender.

\section{O professor subserviente e a perversão do laço formativo}

As condições aviltantes às quais estão submetidos os professores levam-nos a questionar: Por que alguns continuam a exercer a docência em instituições nas quais são privados de se enunciarem? As razões são variadas e vale lembrar a máxima de uma impostura perversa: "quem quer o fim quer os meios" (Serge André,1993, p. 11; tradução nossa). Para alguns 
professores, a docência é um trabalho extra, exercido fora do expediente da profissão liberal, pois encontramos advogados, dentistas, psicólogos, enfermeiros, entre outros profissionais que afirmam viver de "bico". A professora Maria Madalena resume:

"Eu não sou mestre. Não tenho essa titulação. Então, eu sou desejável porque sou bem baratinha. Assim, a gente fica se sentindo prostituta. Vendemos o corpo. Porque... Quando você está na docência, para ela ser uma fonte de renda, você se prostitui. Porque você tem que ter muitas turmas e, quanto mais turmas você tem, menor é a qualidade do seu trabalho, menos você se qualifica, menos você estuda, mais você cumpre tabela" (Professora Maria Madalena, 2017)

Uma faculdade como "bico" não é suficiente, precisa-se de muitos outros e, como a preocupação é prover uma quantidade de carga horária mínima a cada semestre, não se dispõe de tempo suficiente para dar continuidade à formação. Portanto, os profissionais liberais tornam-se menos identificados com a docência. Eles "ganham o pão" interinamente. É um modo particular de exercício da docência, cujo trabalho é "cumprir tabela", tornar-se "aulista". A universidade fornece aos professores uma "estrutura de véu", algo que dá ao professor universitário um status, embora precário, mas sob um certo fetichismo. Como mostra-nos Pimenta e Anastasiou (2010), a passagem para a docência tornou-se um processo que ocorre "naturalmente", pois, de um dia para outro, um profissional tornar-se professor.

Para outros, a docência será um trampolim para a aprovação posterior em um concurso público, após submissão a toda sorte de injúrias e escárnios, como um professor que, decorridos seis meses da entrevista, enviou-me um e-mail dizendo: "Consegui sair daquele inferno [faculdade] e fui aprovado em um concurso" (Professor Amadeus). Nesse caso, a docência possibilitou ao professor uma melhor posição na carreira. Seguindo essa ideia, podemos, então, pensar que o professor, a despeito da depreciação de seu trabalho, abre mão de sua singularidade a ponto de aceitar seguir o gozo do Outro do mercado capitalista. Para Cathelineau (2019, tradução nossa), estamos habituados ao inferno e, ainda assim, preocupados em saber sua causa em nós e no laço social. Esse inferno é mais ameaçador e mais real. A questão é saber porque nós estamos nele.

Há também os professores que declaram que a docência é uma forma de comprometer-se com a formação de novos profissionais. Portanto, têm um compromisso ético-político com a classe, como testemunhou Lucas, um médico: "o aspecto financeiro não me atrai, é ruim [...] Mas ajuda a pagar a minha gasolina [...] Como eu fui bem ensinado, tive bons professores, é uma forma de ensinar os futuros médicos a serem bons". Nota-se, aqui, um exemplo da observação, feita por Leite (2007), de que nas horas vagas os profissionais transvestem-se de professores universitários e podem ser chamados de "professores diletantes", quase sempre movidos por vaidade.

O que há em comum entre esses professores, independentemente das motivações e convicções pessoais, além do queixume, é o fato de que, para poder ter direito ao "ganha pão" da subsistência no mercado da formação universitária, será preciso entrar em uma montagem perversa. Isso representa um certo pacto de cumplicidade com a aparelhagem. O professor terá que fazer parte do jogo do faz de conta. Eis, aqui, a face de uma neurose: que "através de um semblante perverso, o neurótico possa considerar que qualquer preço é bom" (Calligaris, 1991, p. 115). Assim, o professor adere ao modelo para conseguir o alívio decorrente de sua posição de funcionário exemplar, ou seja, ele está disposto a obedecer a qualquer ordem. Para que se declare bem-sucedido esse projeto político supostamente comprometido com a formação 
universitária o professor terá que se investir da condição ora de objeto, ora de instrumento para, assim, poder manter-se no laço formativo perverso.

Empregamos a noção de perversão a partir do debate proposto por Calligaris (1986) que, ao seguir as coordenadas lacanianas de "laço", pergunta se a perversão não é um laço social, isto é, o laço social por excelência. Seguimos, portanto, a trilha de Pacheco-Filho (2017): trata-se de um regime de gozo (estrutura de um discurso) não fundado sobre a renúncia ao gozo, mas sobre a rejeição da castração. Para entender melhor essa posição do professor no laço formativo perverso, usamos como explicação a saída neurótica. Para Freud (1905/1996), a neurose pode ser compreendida como o "negativo" da perversão. Nesse sentido, Calligaris (1986) fundamenta a posição de que o neurótico sonha em ser perverso - uma complacência neurótica para com a montagem perversa. Resumidamente, isso se dá por uma razão:

\footnotetext{
a posição neurótica é muito insatisfatória. No que diz respeito a um gozo ligado à sua posição de objeto, não somente esse gozo é impossível, mas justamente é dele que o neurótico se defende. O gozo que ele tira dessa defesa é insatisfatório, em primeiro lugar, porque não é o outro (Calligaris, 1986, p.14).
}

A perversão pode ser entendida, essencialmente, como uma patologia social e não sexual (Calligaris, 1991). Nesse sentido, o autor não invalida a tese de Freud (1905/1996), mas fornece-nos uma chave de leitura, ao mostrar que a perversão participa de um certo jogo da vida privada. Além disso, "a perversão encontra a sua fenomenologia no campo do social o mais cotidiano, ou seja, tudo o que diz respeito à vida associativa" (Calligaris, 1986, p. 15).

Considerando as condições da docência, diante do laço social construído com base na mercantilização da formação universitária, a montagem perversa consiste no fato de que o professor ocupa uma posição que o permite ter um certo domínio do gozo do Outro do mercado capitalista. Em outros termos, o professor se objetaliza para fazer esse Outro gozar. Não afirmamos que os professores são perversos de estrutura, mas que, nessa cumplicidade perversa, eles se tornam "o objeto que se tornou instrumento e o sujeito do saber sobre o bom uso desse instrumento" (Calligaris, 1986, p. 12). Em suma, concordamos com a afirmação de Lebrun (2019; tradução nossa) de que "a democratização - talvez seja uma generalização - da perversão".

\section{Considerações finais}

O crescimento do número de faculdades privadas que se autodenominam "universidades" e atuam em nome de um igualitarismo perverso revela estritos fins lucrativos. Certas instituições mostram que o seu empenho e compromisso é com a lógica própria do Mercado, isto é, o efeito de ofertar para criar supostas demandas. $\mathrm{O}$ que efetivamente funciona, mas somente para as economias dos empresários. Equivale a dizer que o neoliberalismo, para ser eficiente, faz semblante de discurso do capitalista. Todavia, isso nem sempre representa o interesse em projetos de formação universitária que sejam capazes de construir alternativas de inserção profissional e de promover a transformação e a efetiva igualdade de direitos, tão caros ao ideal democrático e à ideia que sustenta o "projeto" de democratização do acesso ao ensino superior.

Desse modo, esses conglomerados de instituições que desprezam o índice da qualidade da formação não podem ser avaliados pelo mesmo crivo e critério de outros processos formativos que ao longo de décadas vem sendo desenvolvidos, por exemplo, pelas Pontifícias Universidades Católicas (PUC) e por outras instituições reconhecidas pelo seu legado histórico, ao conciliar em sua tradição um ensino articulado com a produção da pesquisa e com as práticas 
de extensão. Reconhecemos também que essas instituições confessionais e filatrópicas buscam na atual configuração sustentar um trabalho sério, a despeito da atual concorrência perversa no mercado da disputa pela formação acadêmico-profissional, em que a redução do preço da mensalidade, a custos módicos, torna-se um chamariz para qualquer cliente, ratificando a máxima de que "tem valor porque vende bem".

É curioso que, no início da década de 1990, Zilles \& Quadros (1993) mostravam-se preocupados com a identidade institucional das Universidades Católicas que já lutavam com muitas dificuldades econômicas, políticas etc. Os autores chegararam à seguinte conclusão: " a maior de todas as dificuldades parece-me ser, no entanto, a crise de identidade... é mais acentuada na América Latina". Nesse contexto latinoamericano, "a prioridade básica é a sobrevivência.... O paradoxo de os alunos, por um lado, exigirem excelência acadêmica no ensino e na pesquisa, é perfeitamente correto, sem, por outro lado, poderem ou quererem arcar com os custos". (Zilles e Quadros, 1993, p. 11).

O presente estudo conduziu-nos à compreensão de que a mercantilização da formação universitária, "à maneira brasileira", produziu uma torção perversa no laço subjetivo entre professor e aluno, pois impossibilitou o genuíno desdobramento desse vínculo, ao passo que induziu, possivelmente, a um quadro de apatia dos alunos e de melancolia do professor, uma vez que este trabalha sob a condição de objeto. Contrariamente ao propalado, a formação universitária veio acompanhada de uma pauperização da qualidade da transmissão e da experiência necessárias à formação acadêmico-profissional. Ademais, os diplomas, atualmente, são desvalorizados no mercado de trabalho. Assim, a pretendida luta contra as desigualdades sociais resultou, exageradamente, naquilo que ela visava combater. O professor, embora submetido ao caráter alienante e repressivo da instituição associado à mercantilização do ensino universitário, transmitiu a mesma demanda inconsciente de fazer gozar o Outro do mercado capitalista.

Por fim, as desigualdades sociais encontram suas raízes no mesmo processo de constituição da nacionalidade que ainda não foi superado, apesar do atual regime "republicano". As transformações que operam pelo laço social contribuem para criar "um regime de gozo", característica própria de um discurso fundado em rejeição ao simbólico. Com efeito, podemos, então, presumir que a propalada democratização do acesso ao ensino universitário, a partir da pretendida universalização, colaborou para forjar a "montagem perversa", seja pelas promessas de trabalho para os professores, seja pela oferta de diploma para os alunos, e tornou-se compatível com o imaginário social disseminado que, em nome de uma perversão, (a)paga a dimensão desejante ${ }^{6}$.

\section{Referências}

Abraham, T. (1997). O neoliberalismo quer ser sociável e se maquia. In R. Goldenberg (Org.). Goza!: capitalismo, globalização e psicanálise (pp.51-60). Salvador, BA: Ágalma.

Alcadipani, R. (2011). Academia e a fábrica de sardinhas. $O \& S$ Salvador, 18 (57), 345-348.

Almeida, F. Naomar; (2010). Educação superior em Lula x FHC: a prova dos números. Recuperado de https://www.cartamaior.com.br

6 Agradecimento à CAPES pelo financiamento da pesquisa e aos ex-orientadores do doutorado, professores Leandro de Lajonquière e Marcelo Ricardo. 
Brasil. Censo Escolar 2018: Principais resultados. Instituto Nacional de Estudos e Pesquisas Educacionais Anísio Teixeira. Recuperado de http://inep.gov.br/educacao.

Bellangé, V. (2007). À consommer avec modération. La Revue Lacanienne, (3), 22-26.

Bourdieu, P., \& Champagne, P. (2008). Os excluídos do interior. In P. Bourdieu (Org.), $A$ miséria do mundo (Azevedo et al, trads., pp. 481-486). Petrópolis, RJ: Vozes. (Trabalho original publicado em 1993).

Calligaris, C. (1991). A sedução totalitária. In L. T de Aragão., C. Calligaris., J.F, Costa., \& O, Souza. (Orgs.). Clínica do social: ensaios (pp. 105-118). São Paulo, SP: Escuta.

Calligaris, C. (1986). Perversão - Um Laço Social? Salvador, BA: Coorperativa Cultural Jacques Lacan.

Carvalho, J. S. F. (2017). Educação, uma herança sem testamento: diálogos com o pensamento de Hannah Arendt. São Paulo, SP: Perspectiva-FAPESP.

Cathelineau, P-C. (2019). L'economie de la jouissance. Paris: Editions EME.

Diniz-Pereira, J. E. (2015). A situação atual dos cursos de licenciatura no Brasil frente à hegemonia da educação mercantil e empresarial. Revista Eletrônica de Educação, 9, (3), 273-280. doi: http://dx.doi.org/10.14244/198271991355

Dunker, C. I. L. (2015). Mal-estar, sofrimento e sintoma: uma psicopatologia do Brasil entre muros. São Paulo, SP: Boitempo.

Figueiredo, L. C. M. (2000). Sobre pais e irmãos: Mazelas da democracia no Brasil. In M. R. Kehl (Org.), Função fraterna (pp. 132-156). Rio de Janeiro, RJ: Relume-Dumará.

Freud, S. (1996). Totem e tabu. In S. Freud, Edição standard brasileira das obras completas de Sigmund Freud. (James Strachey, trad., Vol 13, pp. 13-162). Rio de Janeiro, RJ: Imago. (Texto original publicado em 1913).

Freud, S. (1996). Três ensaios sobre a teoria da sexualidade. In S. Freud, Edição standard brasileira das obras completas de Sigmund Freud (James Strachey, trad., Vol. 7, pp. 119231). Rio de Janeiro, RJ: Imago. (Trabalho original publicado em 1905).

Kehl, M. R. (2002). Quem tem moral com os adolescentes?: Duas hipóteses sobre a crise na educação no século XXI. Trabalho apresentado no Colóquio do Lepsi, (4). Recuperado de http://www.proceedings.scielo.br/scielo

Kehl, M. R. (2000). A fratria órfã: o esforço civilizatório do rap na periferia de São Paulo. In M. R. Kehl, (Org.), Função fraterna (pp.209-244). Rio de Janeiro, RJ: Relume Dumará.

Lacan, J. J. (1992). O seminário, livro 17: O avesso da psicanálise. (Ary Roitman, trad.). Rio de Janeiro: Zahar. (Apresentação oral em 1969-1970, publicação original em 1991).

Lajonquière, L. (2018). As ilusões (psico)pedagógicas e o sonho de uma escola para todos. In M. E, Arreguy., M. B, Coelho \& S, Cabral (Orgs.), Racismo, capitalismo e subjetividade: Leituras psicanalíticas e filosóficas (pp. 59-69). Rio de Janeiro, RJ: EDUFF.

Lajonquière, L. (2013). Figures de l'infantile: La psychanalyse dans la vie quotidienne auprès des enfants. Paris: L’Harmattan/FAPESP (Trabalho original publicado em 2010).

Lajonquière, L. (2011a). Três notas e um epílogo sobre escola, escrita e inclusão. In M. F. LierDevitto, \& L. Arantes (Orgs.), Faces da escrita: linguagem, clínica, escola (pp.189-199). Campinas, SP: Mercado das Letras. 
Lajonquière, L. (2011b). A maestria da palavra e a formação de professores. Eduação \& Realidade, 36(3), 849-865. doi: https://doi.org/10.1590/S2175-62362013000200006

Lajonquière, L. (2009). Infância e ilusão (psico)pedagógica: escritos de psicanálise e educação. Petrópolis, RJ: Vozes.

Lebrun, J. P. (2019). Où est passée la perversion? Recuperado de https://www.freudlacan.com/getpagedocument $/ 27770$

Leite, R. (2000, 1 de outubro). As sete pragas da universidade revisitadas. Folha de S. Paulo, São Paulo, Caderno Opinião.

Lo Bianco, A. C. (2010). O saber inconsciente e o saber que se sabe nos dias de hoje. Ágora, 13(2), 165-173.

Pereira, M. R. (2019). Será mesmo que o magistério atual é formado pela "seleção dos péssimos"? ETD - Educação Temática Digital. 21(2), 333-347. doi: https://doi.org/10.20396/etd.v21i2.8650480

Pereira, M. R., \& Gurski, R. A. (2019). A adolescência generalizada como efeito do discurso do capitalista e da adultez erodida. Psicologia \& Sociedade, 26(2), 376-383. doi: https://doi.org/10.1590/S0102-71822014000200014

Pimenta, S. G., \& Anastasiou, L. G. C. (2010). Docência no ensino superior. São Paulo, SP: Cortez.

Racamier, P. C. (2010). L'inceste et l'incestuel. Paris: Dunon.

Santos, B. de S. (2011). A encruzilhada da universidade europeia. Ensino Superior: Revista do SNESup, (41). 1-8. Recuperado de http://www.snesup.pt

Helena, S. (2011). O setor privado de ensino superior no Brasil: continuidades e transformações. Revista Ensino Superior Unicamp. Recuperado de https://www.revistaensinosuperior.gr.unicamp.br/artigos/

Sampaio, S. M. R. (2011). Observatório da vida estudantil: primeiros estudos. Salvador, BA: EDUFBA.

Sena, I. J. (2020). Os impasses do ensino superior privado brasileiro: o professor e a perversão do laço formativo [Atualidades]. Estilos da Clínica, 25(1), 188-189. doi: https://doi.org/10.11606/issn.1981-1624.v25i1p188-189

Teixeira, C. F, \& Almeida, S. F. C. de (2016). A Nova Ordem Simbólica e suas repercussões na função docente no Ensino Superior. In C. P. de Medeiros \& S. F. C de Almeida (Orgs.). Psicanálise implicada: educar e tratar o sujeito (pp. 65-89). Curitiba, PR: Juruá.

Teixeira, C. C. F. (2013). A nova ordem simbólica e suas repercussões na função docente, no ensino superior. Dissertação de Mestrado, Faculdade de Educação, Universidade de Brasília, Brasília, DF.

Zilles, U, \& Quadros, O. J. (1993). Identidade, desafios e futuro das Universidades Católicas. Porto Alegre, RS: EDIPUCRS.

Voltolini, R. (2019). Escola consumida ou consumada? Estilos da Clínica, 24(1), 1-3. doi: https://doi.org/10.11606/issn.1981-1624.v24i1p1-3

Revisão gramatical: Aline Carvalho Cerqueira

E-mail: alinecarvace@outlook.com

Recebido em junho de 2020 - Aceito em setembro de 2020. 